\title{
The effects of vasoactive intestinal peptide on RANKL-induced osteoclast formation
}

\author{
Hongyi Qu ${ }^{1,2}$, Yan Zhuang ${ }^{1}$, Lin Zhu' ${ }^{1}$ Zuohui Zhao ${ }^{2}$, Kelai Wang ${ }^{1}$ \\ ${ }^{1}$ Department of Pediatric Surgery, Qilu Hospital, Cheeloo College of Medicine, Shandong University, Jinan, China; ${ }^{2}$ Department of Pediatric \\ Surgery, The First Affiliated Hospital of Shandong First Medical University (Shandong Provincial Qianfoshan Hospital), Jinan, China \\ Contributions: (I) Conception and design: H Qu, K Wang; (II) Administrative support: K Wang; (III) Provision of study materials or patients: Y \\ Zhuang, L Zhu; (IV) Collection and assembly of data: H Qu, Z Zhao; (V) Data analysis and interpretation: H Qu, Z Zhao; (VI) Manuscript writing: \\ All authors; (VII) Final approval of manuscript: All authors. \\ Correspondence to: Kelai Wang. Department of Pediatric Surgery, Qilu Hospital, Cheeloo College of Medicine, Shandong University, Jinan, China. \\ Email: qhy13905316435@163.com.
}

Background: Congenital pseudarthrosis of the tibia is a rare disease characterized by an imbalance in bone remodeling. Vasoactive intestinal peptide (VIP) has been proven to modulate bone resorption and the formation of osteoclasts. This study aimed to explore the effects of VIP on the homeostasis of bone metabolism in diverse in vitro systems.

Methods: Bone marrow-derived macrophages (BMMs) were differentiated into tartrate-resistant acid phosphatase-positive cells through incubation with receptor activator of nuclear factor $\kappa \mathrm{B}$ ligand (RANKL) and macrophage colony-stimulating factor (M-CSF). In vitro resorption pit detection was carried out to assess the effects of VIP on osteoclastic activity. Rat osteosarcoma cell line ROS 17/2.8 was cultured alone or co-cultured with rat BMMs in the presence or absence of VIP at various concentrations. The expression levels of RANKL, RANK, OPG, NF-кB, IL-6, ERK, CAII, and GAPDH were determined by qRT-PCR and WB assay.

Results: VIP was observed to repress osteoclast differentiation without affecting the number of osteoclast precursor cells. Furthermore, the modulation of the RANKL/osteoprotegerin (OPG), nuclear factor- $\kappa \mathrm{B}$ $(\mathrm{NF}-\kappa \mathrm{B})$, and extracellular signal-regulated kinase (ERK) signaling pathways were involved in the inhibitive influence of VIP upon bone erosion. Additionally, VIP affected the expression levels of osteoclastic factors including RANKL, $O P G$, and interleukin-6 in osteoblast cells. Furthermore, the expression levels of RANKL and $R A N K$ were increased, while $O P G$ expression was reduced after treatment with VIP in the co-culture of ROS 17/2.8 and rat BMMs. ERK and NF- $\mathrm{BB}$ signal pathways were demonstrated to be involved in the effect of VIP in the co-culture system.

Conclusions: VIP plays a critical role in bone remodeling and might serve as a potential target in the development of treatments for congenital pseudarthrosis of the tibia.

Keywords: Congenital pseudarthrosis of the tibia; vasoactive intestinal peptide (VIP); osteoclast; RANKL; osteoprotegerin

Submitted Sep 27, 2020. Accepted for publication Jan 22, 2021.

doi: $10.21037 /$ atm-20-7607

View this article at: http://dx.doi.org/10.21037/atm-20-7607

\section{Introduction}

Bone tissue predominantly consists of osteocytes, osteoclasts, osteoblasts, and intracellular matrix proteoglycans. Bone metabolism is a highly coordinated remodeling process that balances the bone resorption and bone formation activities of osteoclasts (1-3). Abnormal bone remodeling can lead to illnesses such as osteopetrosis (4), osteoporosis (5), and 
congenital pseudarthrosis of tibia (CPT) (6). Congenital pseudarthrosis of tibia usually presents as tibial bending deformity or fracture of tibia and/or fibula, and it is easy to repeatedly fracture and nonunion, thus forming pseudo joint. There should be some factors leading to the imbalance of bone remodeling.

Osteoblasts are not only crucial for bone mineralization and matrix biosynthesis, but also for the production of cytokines that contribute to the differentiation, survival, and proliferation of osteoclasts (7). Persson et al. reported that vasoactive intestinal peptide (VIP) promotes the expression of interleukin (IL)-6 in mouse calvarial osteoblasts but has no effect on the expression levels of Oncostatin M, IL-11, or leukemia inhibitory factor (LIF) (8).

Multinucleated osteoclasts play a pivotal role in the progression of CPT $(9,10)$. Receptor activator of nuclear factor-k (RANK) is a type I transmembrane protein, belonging to the tumor necrosis factor (TNF) receptor family. It is expressed on many cell surfaces, such as osteoclast precursor, mature osteoclast, etc. Receptor activator of nuclear factor-k B ligand (RANKL) is the related ligand of RANK. RANKL is a TNF ligand, which can be produced by osteoblasts and their precursors, $\mathrm{T}$ cells, B cells and megakaryocytes. RANKL and macrophage colony-stimulating factor (M-CSF) play critical roles in osteoclast differentiation and are abundant in stromal cells and osteoblasts (11-13). M-CSF is indispensable to the viability of osteoclast precursors and enhances the expression of the RANKL receptor $R A N K(14,15)$. The interaction between RANK and RANKL plays a pivotal role in the activation and differentiation of osteoclasts $(12,13)$. The deficiency of RANKL, M-CSF, or RANK in mice is characterized by osteoclast deficiency, which eventually leads to osteopetrosis (16-19).

Osteoprotegerin (OPG), which is released by stromal cells and osteoblasts, can effectively inhibit osteoclastogenesis by functioning as a soluble decoy receptor of RANKL. The RANKL/OPG ratio is a key index of bone resorption and osteoclastogenesis under the physiological conditions of bone metabolism. Targeted silencing of $O P G$ in mice results in the development of excessive osteoclasts, decreased trabecular bone volume, and multiple bone fractures (20). Therefore, the regulation of osteoclasts differentiation and activation could become a promising strategy for preventing bone erosion in patients with CPT.

The functions of osteoclasts and osteoblasts are modulated by a number of systemic hormones including
1,25(OH)2-vitamin D3 (D3) and parathyroid hormone $(\mathrm{PTH})$, as well as various local factors including growth factors and osteotropic cytokines (21-24). The results of a previous study indicated that a network of peptidergic nerve fibers exists in skeletal bone tissues, and that these skeletal nerves release neuropeptides that can modulate the activities of osteoblasts and osteoclasts (25). Hence, we postulated that neuro-osteogenic interactions are vital determinants of abnormal bone remodeling in CPT.

VIP, a member of the secretin-glucagon family, is a 28-amino-acid peptide that is mostly expressed by immune and endocrine cells, and is present in the peripheral and central nervous systems $(26,27)$. The presence of VIP in bone marrow, the epiphyseal growth plate, and nerve fibers in the periosteum suggests that it is involved in neuro-osteogenic interactions in the skeleton (28-30). VIP participates in the regulation of bone metabolism by binding with its receptor. VIP receptors exist on the surface of osteoblasts and osteoclasts $(31,32)$. The regulation of VIP on bone metabolism is mainly regulated by osteoclast differentiation, formation and bone resorption through binding with receptors $(33,34)$.

Our previous study found that VIP expression was enhanced in osteoclasts at the fracture end of CPT (35), while VIP could promote osteoclast bone resorption activity. Therefore, it is speculated that VIP may participate in the occurrence and development of CPT, but the underlying mechanism is unknown. As bone erosion is considered to be a critical pathological feature of CPT, the present study was designed to test our hypothesis that VIP plays a vital role in the modulation of osteoclast formation and activation (34). Specifically, we aimed to explore the effects of VIP treatment on the homeostasis of bone metabolism in various in vitro systems.

We present the following article in accordance with the MDAR reporting checklist (available at http://dx.doi. org/10.21037/atm-20-7607).

\section{Methods}

\section{Materials}

VIP was purchased from Nanjing Peptide Biotechnology Inc. (Nanjing, China). Fetal bovine serum (FBS), a modification of Minimum Essential Medium (a-MEM), and L-glutamine were supplied by Invitrogen (Carlsbad, USA). Oligonucleotide primers were ordered from Sangon Biotech (Shanghai, China). TaqMan Universal PCR Master 
Mix and probes were obtained from Applied Biosystems (Foster City, CA). Anti-RANKL, anti-RANK, anti-OPG, anti-NF- $\kappa \mathrm{B}$, anti-interleukin 6 (IL-6), anti-ERK, anticarbonic anhydrase II (CAII), anti-glyceraldehyde-3phosphate dehydrogenase (GAPDH) primary, and antiIgG-horseradish peroxidase secondary antibodies were purchased from Bioss Biotechnology, Inc. (Beijing, China).

\section{Isolation of osteoclast precursors and osteoclast formation}

Three-week-old male Sprague Dawley (SD) rats were purchased from Shandong Provincial Center for Disease Control and Prevention (Jinan, China) and maintained under specific pathogen-free conditions. All animal experiments were performed in accordance with the guidelines for animal care and approved by The First Affiliated Hospital of Shandong First Medical University.

Bone marrow was collected as previously described (34). Briefly, under aseptic conditions, the tibia and femur were removed from the rat, and the adhering tissues were dissected. Then, the ends of the bones were removed, and a syringe was used to rinse out the bone marrow. Cells were collected in $\alpha$-MEM supplemented with $10 \% \mathrm{FBS}$, nucleoside, and $1 \%$ penicillin and streptomycin (Invitrogen, USA). Red blood cells were removed with phosphatebuffered saline (PBS) solution treatment. Cells derived from the bone marrow were continuously cultured in primary culture medium complemented with recombinant M-CSF (PeproTech, NJ). Then, non-adherent cells were further inoculated onto culture dishes and cultivated for 72 hours in medium supplemented with $30 \mathrm{ng} / \mathrm{mL}$ M-CSF, and further adherent cells were regarded as bone marrow-derived macrophages (BMMs). For the osteoclast differentiation assay, BMMs were cultivated for 72 hours with $50 \mathrm{ng} / \mathrm{mL}$ RANKL and $30 \mathrm{ng} / \mathrm{mL}$ M-CSF in the presence or absence of VIP at various concentrations. Tartrate-resistant acid phosphatase (TRAP)-positive polynuclear cells were regarded as osteoclasts.

\section{Culture of osteosarcoma cell line ROS 17/2.8 and co- culture with osteoclast precursors}

The rat osteosarcoma cell line ROS 17/2.8 was incubated in $\alpha$-MEM mixed with L-glutamine, $10 \% \mathrm{FBS}$, and $1 \%$ penicillin and streptomycin at $37{ }^{\circ} \mathrm{C}$ with $5 \% \mathrm{CO}_{2}$. ROS $17 / 2.8$ cells were inoculated into 10 -cm culture dishes at a density of $(3-5) \times 10^{4}$ cells $/ \mathrm{cm}^{2}$, and the medium was changed every 48 hours. Rat BMMs and ROS 17/2.8 cells (10,000:25,000 ratio) were co-cultivated in $\alpha$-MEM supplemented with $10 \% \mathrm{FBS}$ and $1 \%$ penicillin and streptomycin.

\section{Cell viability assay}

Cell viability was analyzed using an MTT kit (Beyotime Biotechnology, Jiangsu, China) in accordance with the manufacturer's protocol. BMMs were inoculated onto 96well plates with $\alpha$-MEM supplemented with $1 \%$ penicillin and streptomycin and 10\% FBS, with exposure to $50 \mathrm{ng} / \mathrm{mL}$ RANKL and $30 \mathrm{ng} / \mathrm{mL} \mathrm{M-CSF}$ for 72 hours. The cells were then rinsed with $\alpha$-MEM and subjected to further culture with VIP at various concentrations $\left(10^{-9} \mathrm{M}, 10^{-8} \mathrm{M}\right.$, $10^{-7} \mathrm{M}$, or $10^{-6} \mathrm{M}$ ) under inducement with $30 \mathrm{ng} / \mathrm{mL}$ M-CSF and $50 \mathrm{ng} / \mathrm{mL}$ RANKL for $6,12,24$, or $48 \mathrm{~h}$. After 24 hours, $20 \mu \mathrm{L}$ of freshly made MTT was added to the culture and incubated for 4 hours at $37^{\circ} \mathrm{C}$. Then, the supernatant was discarded and the pellet was dissolved in $150 \mu \mathrm{L}$ dimethyl sulfoxide. Finally, the absorbance value was determined at $570 \mathrm{~nm}$ using an enzyme-linked immunosorbent assay (ELISA) reader (Thermo Fisher Scientific Inc., China).

\section{TRAP staining}

TRAP staining was conducted to assess the formation of osteoclasts. BMMs were inoculated at a density of $1.5 \times 10^{4}$ cells/well onto 48 -well culture plates and exposed to $30 \mathrm{ng} / \mathrm{mL}$ M-CSF and $50 \mathrm{ng} / \mathrm{mL}$ RANKL for 72 hours. The BMMs were then fixed in $3.7 \%$ formalin and permeabilized with $0.1 \%$ Triton $\mathrm{X}-100$. TRAP staining was conducted using a leukocyte acid phosphatase kit (SigmaAldrich, St. Louis, MO, USA) following the manufacturer's protocol. The total number of cells with 3 or more nuclei on each 48-well plate was taken as the number of osteoclasts. Micrographs were acquired with a fluorescence microscope.

\section{Preparation of bovine bone slices}

An Isomet LowSpeed Saw (Buehler, Lake Bluff, IL) and a hand-held saw (Dremel, Racine, WI) were used to cut bovine cortical bone into $4 \times 4 \mathrm{~mm}$ slices with a thickness of $70 \mu \mathrm{m}$. The bone slices were subjected to sterilization with $70 \%$ ethanol and were maintained in PBS overnight at room temperature. After that, the slices were washed in PBS and culture medium consecutively, and then transferred to 
96-well plates and covered with $50 \mu \mathrm{L}$ medium for further incubation.

\section{Resorption pit assays}

A resorption pit assay was performed to detect the osteoclast formation and activity. Briefly, cells were inoculated at a density of $2 \times 10^{4}$ cells/well into 96-well plates containing a slice of bovine bone with various concentrations of VIP $\left(10^{-8} \mathrm{M}\right.$ or $\left.10^{-7} \mathrm{M}\right)$ and $50 \mathrm{ng} / \mathrm{mL}$ RANKL and $30 \mathrm{ng} / \mathrm{mL}$ M-CSF for 3 weeks. A cotton bud was used to rub cells onto the bovine bone slices, and the slices were subjected to staining with toluidine blue. The number of pits in the bovine bone slices resulting from bone erosion was counted.

\section{$R N A$ isolation and real-time polymerase chain reaction}

Total RNA was purified from osteoclasts and osteoblasts using TRIzol reagent (Invitrogen, USA). Following this, reverse transcription was carried out with a PrimeScript ${ }^{\mathrm{TM}}$ RT Reagent Kit in accordance with the manufacturer's

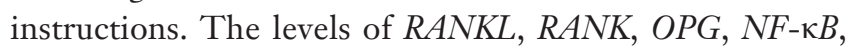
$I L-6, E R K, C A I I$, and GAPDH mRNA were determined by performing a quantitative real-time polymerase chain reaction (qRT-PCR) assay using an SYBR Green PCR kit (Takara, China) and an ABI Prism 7900 System (Applied Biosystems, Waltham, MA) in accordance with the manufacturer's instructions. GAPDH was chosen as the internal control for RNAs. The $2^{-\Delta \Delta \mathrm{Ct}}$ method was adopted to detect the relative expression levels of genes. All experiments were performed in triplicate.

\section{Western blot}

RIPA lysis buffer (Beyotime Biotechnology, China) supplemented with $1 \%$ protease inhibitors (Pierce, Texas) was used to isolate protein from the tissues and cells according to standard procedures. The isolated samples were subjected to separation through $12 \%$ sodium dodecyl sulfate-polyacrylamide gel (SDS-PAGE) electrophoresis and were then transferred to polyvinylidene difluoride membranes. The membranes were incubated with specific primary antibodies against RANKL, RANK, OPG, NF- $\kappa$, IL-6, ERK, CAII, and GAPDH for 12 hours at $4{ }^{\circ} \mathrm{C}$, which was followed by probing with the matching secondary antibodies conjugated with horseradish peroxidase $(1: 3,000$, Abcam) for 1 hour at $37^{\circ} \mathrm{C}$. The blots were developed with Western Lighting Plus-ECL and a gray-scale analysis of the detected protein bands was performed using Quantity One analysis software (Bio-Rad, USA).

\section{Statistical analysis}

Data were exhibited as mean \pm standard deviation (SD). SPSS 16.0 software (Chicago, IL) was employed to perform all statistical analysis. Differences between groups were assessed by performing one-way analysis of variance (ANOVA) with the Student-Newman-Keuls post-hoc test and two-tailed Student's $t$-tests. $\mathrm{P}<0.05$ was regarded as being statistically significant.

\section{Results}

\section{Influence of VIP on osteoclast differentiation}

A rat $\mathrm{BMM}$ culture system was utilized to investigate whether VIP modulates osteoclast formation. The differentiation of BMMs into multinucleated TRAP-positive cells was induced with RANKL and M-CSF (Figure 1A,B). Active osteoclasts are characterized by the ability of forming resorption pits in bone tissue. To evaluate whether osteoclastic activity is affected by treatment with VIP, a resorption pit assay was performed using a slice of bovine bone. A number of resorption pits were observed in bone slices exposed to RANKL-treated cells. However, VIP treatment inhibited the formation of resorption pits generated by cells treated with RANKL in a dose- and timedependent manner (Figure 2A,B). The number of resorption pits was reduced by $70 \%$ after treatment with $10^{-7} \mathrm{M}$ VIP compared to control peptide (Figure 2C). Together, these results suggested that VIP treatment leads to decreased bone resorption by exerting an anti-osteoclastogenic influence on precursor cells derived from bone marrow.

\section{Effect of VIP on RANKL-mediated survival of osteoclast precursor cells}

To assess the effects of VIP on the proliferation of rat BMMs, MTT assays were carried out to evaluate cell growth after inducement with $50 \mathrm{ng} / \mathrm{mL}$ RANKL and $30 \mathrm{ng} / \mathrm{mL}$ $\mathrm{M}-\mathrm{CSF}$ in the absence or presence of VIP at various concentrations $\left(10^{-9} \mathrm{M}, 10^{-8} \mathrm{M}, 10^{-7} \mathrm{M}\right.$, or $\left.10^{-6} \mathrm{M}\right)$ for 6 , 12, 24, or 48 hours. As shown in Figure 3, no difference was observed in the proliferation of osteoclast precursor cells treated with VIP, regardless of the dose or treatment time, compared to the control group $(\mathrm{P}<0.05)$. 

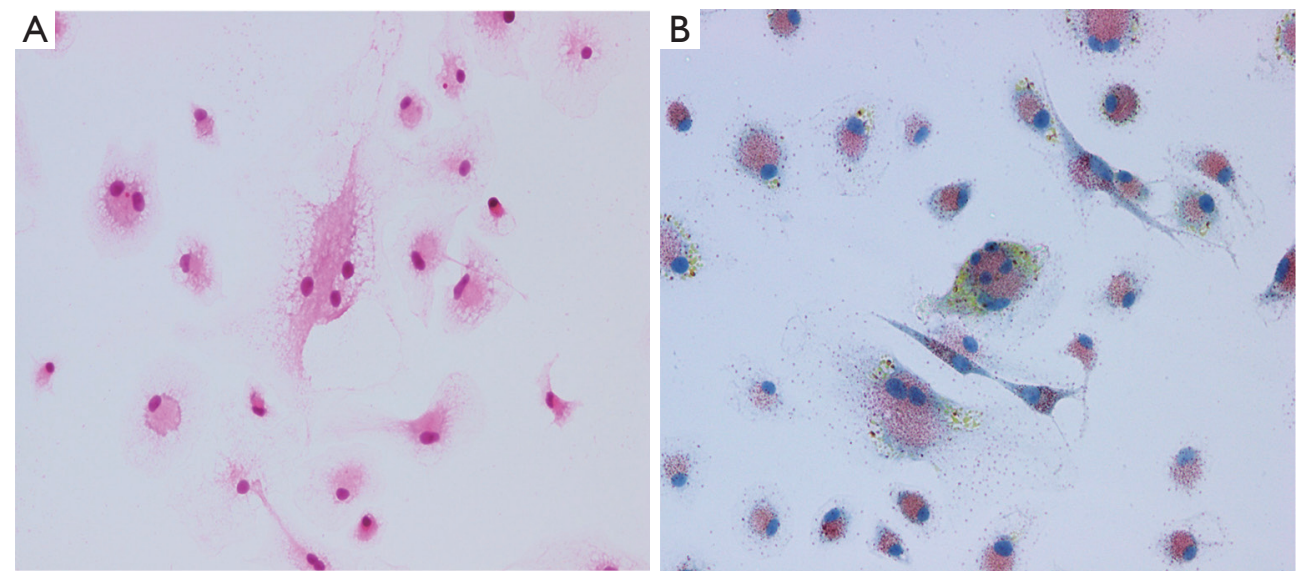

Figure 1 Identification of rat osteoclast formation. The differentiation of BMMs into multinucleated TRAP-positive cells was induced with $50 \mathrm{ng} / \mathrm{mL}$ RANKL and $30 \mathrm{ng} / \mathrm{mL}$ M-CSF. (A) Image of hematoxylin and eosin (HE) staining to detect osteoclast formation; (B) TRAP staining for osteoclasts with 3 or more nuclei. Magnification, $\times 200$. BMMs, bone marrow-derived macrophages; TRAP, tartrate-resistant acid phosphatase; RANKL, receptor activator of nuclear factor $\kappa \mathrm{B}$ ligand; M-CSF, macrophage colony-stimulating factor.

\section{$V I P$ affects the expression of RANK, RANKL, and OPG in rat osteoclasts}

To investigate the function of VIP in the modulation of $R A N K, R A N K L$, and $O P G$ expression in rat osteoclasts, rat BMMs were treated with various concentrations of VIP $\left(10^{-9} \mathrm{M}, 10^{-8} \mathrm{M}, 10^{-7} \mathrm{M}\right.$, or $\left.10^{-6} \mathrm{M}\right)$ exposed to $30 \mathrm{ng} / \mathrm{mL}$ $\mathrm{M}-\mathrm{CSF}$ and $50 \mathrm{ng} / \mathrm{mL}$

RANKL for 48 hours. The qRT-PCR results revealed that the expression levels of $R A N K L$ and $R A N K$ were decreased after VIP treatment (Figure $4 A, B$ ), whereas the level of $O P G$ transcripts was increased (Figure $4 C$ ). Moreover, the ratio of $R A N K L / O P G$ mRNA expression was reduced in a dosedependent way (Figure $4 D$ ). Western blotting was performed to examine the effect of VIP on the protein abundance of RANK, RANKL, and OPG (WB) (Figure 4E). The results indicated that the protein levels of RANK, RANKL were decreased after VIP treatment (Figure $4 F, G$ ), whereas the level of OPG expression was increased (Figure 4H). Additionally, the ratio of RANKL/OPG protein expression was diminished in a dose-dependent way (Figure 4I).

\section{VIP suppresses the ERK and NF- $\mathrm{KB}$ signaling pathways in RANKL-induced osteoclast formation}

To illuminate the underlying mechanisms and signaling pathways involved in the activity of VIP in osteoclast differentiation, the expression levels of NF- $\mathrm{KB}$ and ERK signaling pathway-related genes were measured in the BMMs treated with various doses of VIP. The qRT-PCR results revealed that incubation with VIP resulted in decreased $N F-\kappa B, I L-6, E R K$, and CAII mRNA levels (Figure $5 A, B, C, D$ ). The effects of VIP on NF- $\mathrm{BB}$, IL-6, ERK, and CAII protein expression were assessed through western blotting (Figure 5E). The results revealed that the protein levels of NF- $\mathrm{BB}, \mathrm{IL}-6, \mathrm{ERK}$, and CAII were decreased after VIP treatment (Figure 5F,G,H,I). These results suggested that the ERK and NF- $\mathrm{KB}$ signaling pathways participate in regulation of osteoclast differentiation and that these pathways are suppressed by treatment with VIP.

\section{$V I P$ affects the expression levels of RANKL, IL-6, and OPG in osteoblastic cell line ROS 17/2.8}

To investigate the function of VIP in the regulation of $R A N K L, I L-6$, and $O P G$ expression in osteoblasts, ROS $17 / 2.8$ cells were incubated with various doses of $\operatorname{VIP}\left(10^{-7} \mathrm{M}\right.$, $10^{-8} \mathrm{M}$ ) for 48 hours. The results showed that VIP treatment elevated the expression levels of RANKL (Figure 6A), whereas the levels of $O P G$ mRNA expression were decreased (Figure 6B). Moreover, the ratio of $R A N K L / O P G$ mRNA expression was found to be augmented in a dosedependent way (Figure 6C). The mRNA expression of $I L-6$ was also increased by treatment with VIP, which indicated the activation of the NF- $\mathrm{kB}$ signaling pathway (Figure $6 D$ ). The effects of VIP on RANKL, IL-6, and $O P G$ protein expression were measured by western blotting (Figure $6 E$ ), and the results showed that the protein expression levels 
A

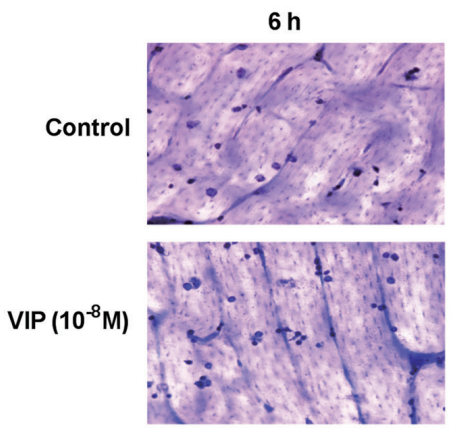

$\operatorname{VIP}\left(10^{-7} \mathrm{M}\right)$

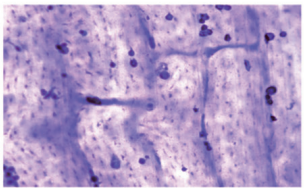

B

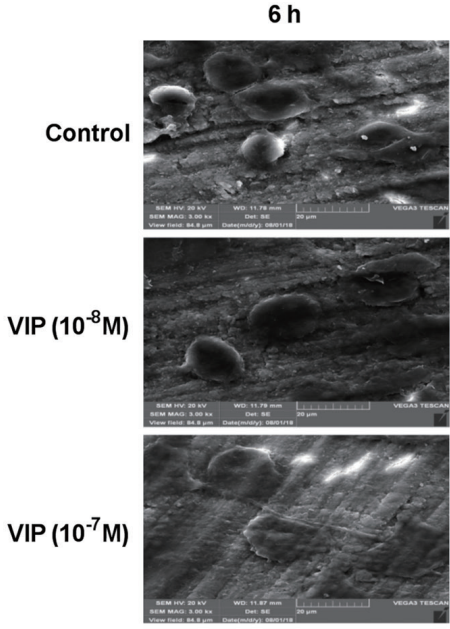

$12 \mathrm{~h}$
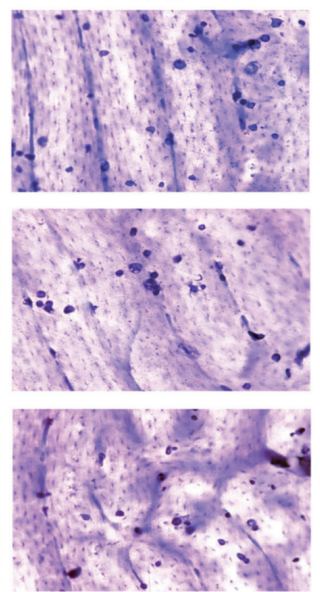

$12 \mathrm{~h}$
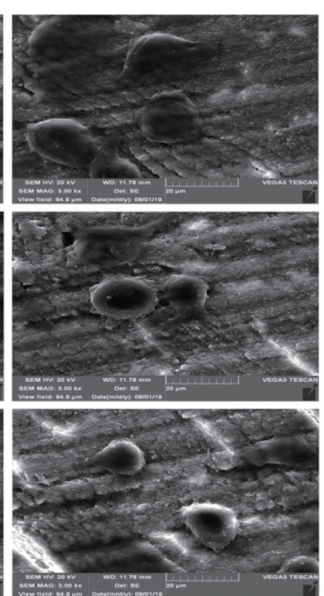

$24 \mathrm{~h}$
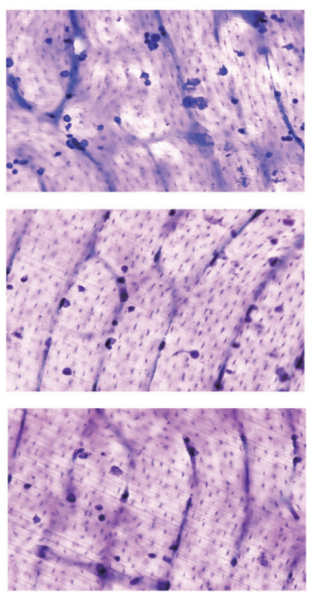

$24 \mathrm{~h}$
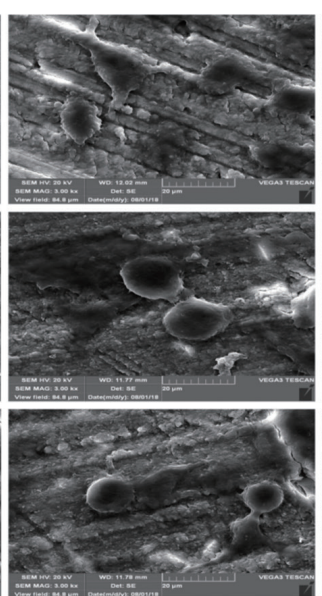

$48 \mathrm{~h}$
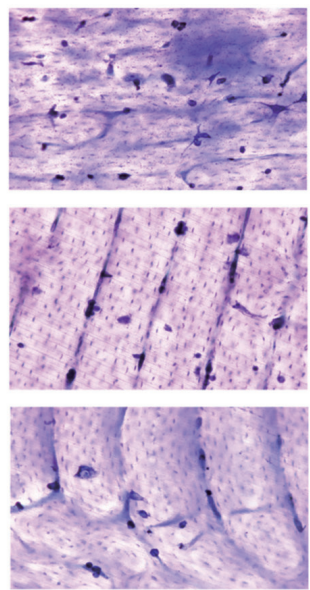

$48 \mathrm{~h}$

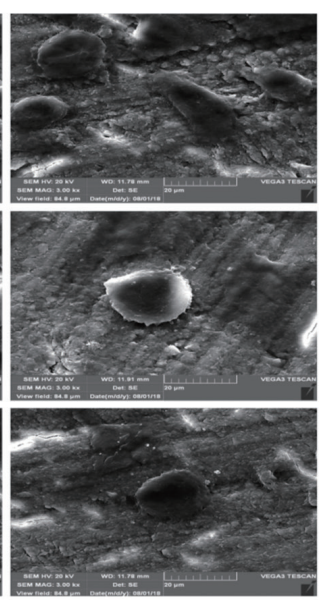

C

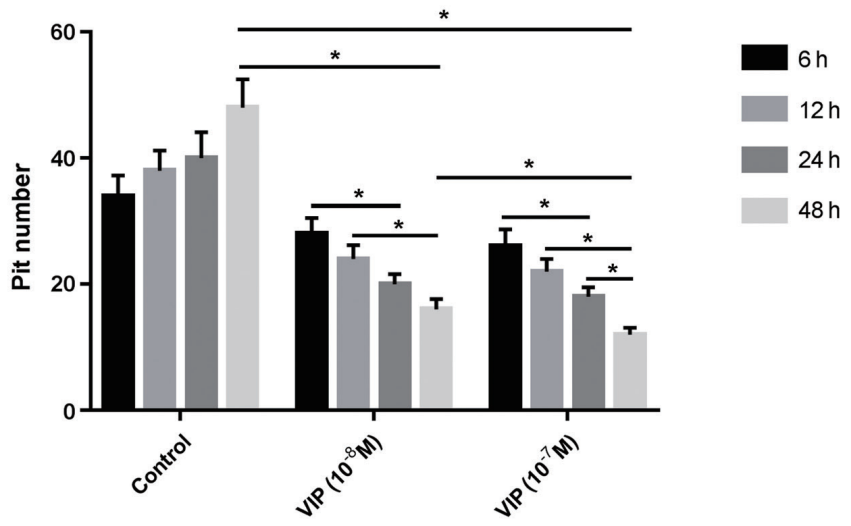

Figure 2 VIP affects the bone resorption activity of rat osteoclasts. Rat BMMs were placed on bovine bone slices and cultured with $50 \mathrm{ng} / \mathrm{mL}$ RANKL and $30 \mathrm{ng} / \mathrm{mL}$ M-CSF in the absence or presence of VIP $\left(10^{-8} \mathrm{M}, 10^{-7} \mathrm{M}\right)$ for $6,12,24$, or 48 hours. (A) Image of representative toluidine blue staining of bone slices (magnification, $\times 200$ ); (B) transmission image of representative resorption pits generated by rat osteoclasts; $(\mathrm{C})$ resorption pit numbers were counted. *, $\mathrm{P}<0.05$. VIP, vasoactive intestinal peptide; BMMs, bone marrow-derived macrophages; M-CSF, macrophage colony-stimulating factor. 


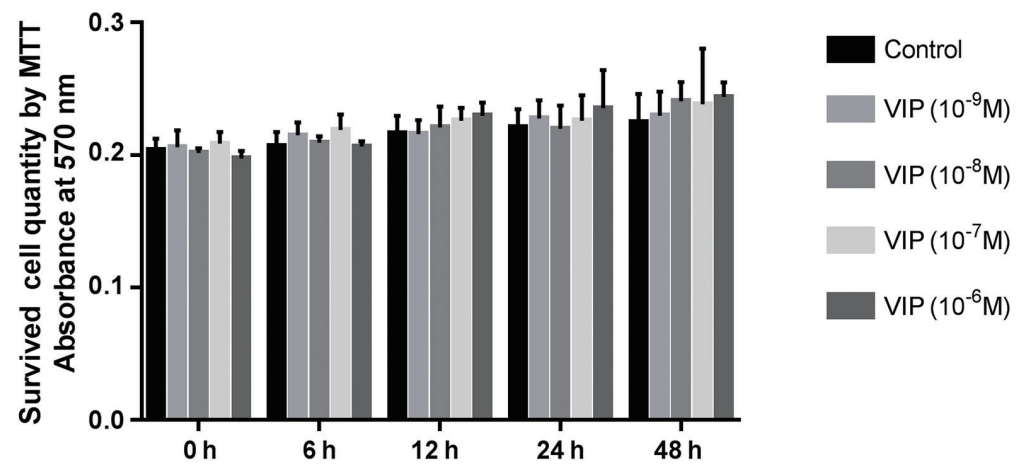

Figure 3 Effect of VIP on RANKL-mediated survival of osteoclast precursor cells. Rat BMMs were incubated in a 96-well plate with $50 \mathrm{ng} / \mathrm{mL}$ RANKL and $30 \mathrm{ng} / \mathrm{mL}$ M-CSF in the absence or presence of VIP $\left(10^{-9} \mathrm{M}, 10^{-8} \mathrm{M}, 10^{-7} \mathrm{M}, 10^{-6} \mathrm{M}\right)$ for $6,12,24$, or 48 hours. Cell viability analysis was performed using an MTT kit. Data were acquired from three independent experiments. VIP: Vasoactive intestinal peptide; RANKL: Receptor activator of nuclear factor $\kappa$ B ligand; BMMs, bone marrow-derived macrophages; M-CSF, macrophage colonystimulating factor.

of $R A N K L, I L-6$, and $O P G$ showed the same tendency as the mRNA expression levels (Figure 6F, G,H,I). These data indicated that the expression of osteoclastic factors including RANKL, OPG, and IL-6 were affected by VIP in osteoblast cells.

\section{VIP affects RANK, RANKL, and OPG expression in the co-culture of ROS 17/2.8 and rat osteoclast precursor cells}

To investigate the function of VIP in the modulation of $R A N K, R A N K L$, and $O P G$ expressions in ROS $17 / 2.8$ and rat osteoclast precursor cell co-culture, the co-cultures were treated with various doses of VIP $\left(10^{-7} \mathrm{M}, 10^{-8} \mathrm{M}\right)$ for 48 hours exposed to $30 \mathrm{ng} / \mathrm{mL}$ M-CSF and $50 \mathrm{ng} / \mathrm{mL}$ RANKL. The qRT-PCR results revealed that VIP treatment augmented the mRNA levels of $R A N K L$ and $R A N K$ (Figure $7 A, B$ ), but it reduced the levels of $O P G$ mRNA expression (Figure $7 C$ ). The ratio of $R A N K L / O P G$ mRNA expression was also augmented in dose-dependent way (Figure 7D). The effects of VIP treatment on RANK, RANKL, and OPG protein expression were assessed by western blot (Figure 7E). Protein expression data suggested that the protein expression levels of RANK, RANKL were increased after VIP treatment (Figure 7F,G), whereas the level of OPG expression was decreased (Figure $7 H$ ). The ratio of RANKL/OPG protein expression was also increased in dose-dependent way (Figure 7I). These data indicated that the expression levels of osteoclastic factors such as RANKL and RANK were increased, whereas the expression of OPG was repressed by VIP in ROS 17/2.8 and rat osteoclast precursor cell co-culture.

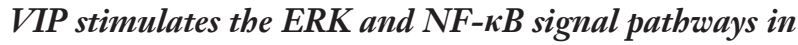 ROS 17/2.8 and rat osteoclast precursor cell co-culture induced by $R A N K L$}

To verify the underlying mechanisms and signaling pathways involved in the effect of VIP on the co-culture system, we evaluated the expression levels of $\mathrm{NF}-\kappa \mathrm{B}$ and ERK signal pathways in our co-culture system after treatment with VIP $\left(10^{-8} \mathrm{M}, 10^{-7} \mathrm{M}\right)$ under inducement with $30 \mathrm{ng} / \mathrm{mL}$ M-CSF and $50 \mathrm{ng} / \mathrm{mL}$ RANKL for 48 hours. The qRT-PCR results revealed that incubation with VIP augmented the mRNA levels of $N F-\kappa B, I L-6, E R K$, and CAII (Figure $8 A, B, C, D$ ). The influence of VIP on the protein expression levels of NF- $\kappa$ B, IL-6, ERK, and CAII were detected by western blotting (Figure $8 E$ ), and the protein levels showed a similar tendency to the mRNA levels (Figure 8F, $, H, I$ ). These data indicated that the ERK and $\mathrm{NF}-\kappa \mathrm{B}$ signaling pathways participate in the regulation of increased osteoclast differentiation induced by VIP in the $\operatorname{ROS} 17 / 2.8$ and rat osteoclast precursor cell co-culture system.

\section{Discussion}

CPT is a rare illness with a reported incidence of approximately $1: 140,000$ to $1: 250,000$ (36). It is usually associated with neurofibromatosis and is also observed in some cases of Campanacci's osteofibrous dysplasia and 
A

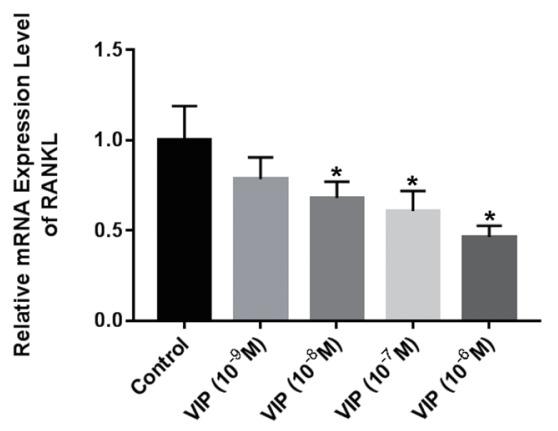

D

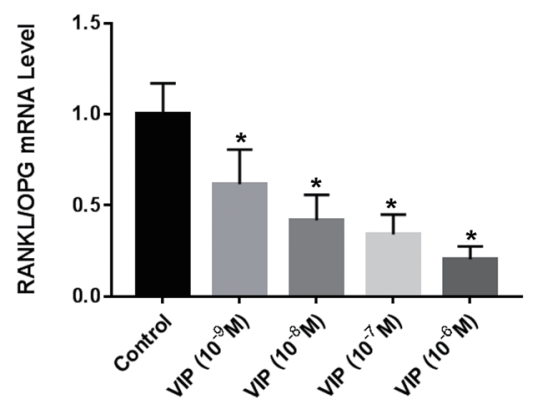

G

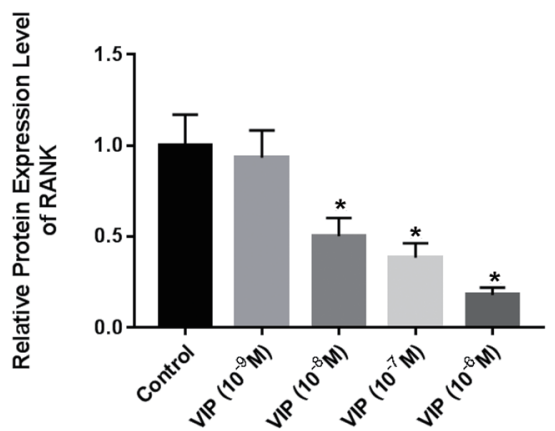

B

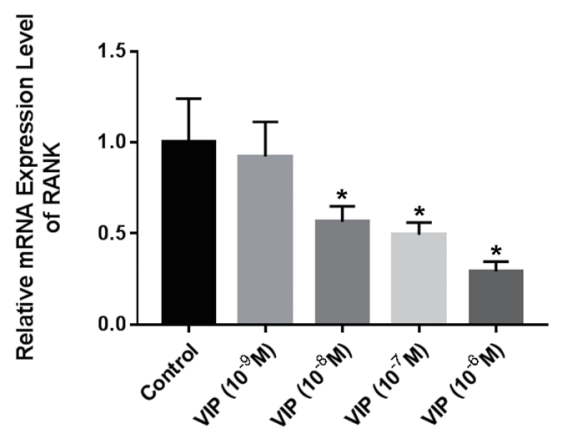

E

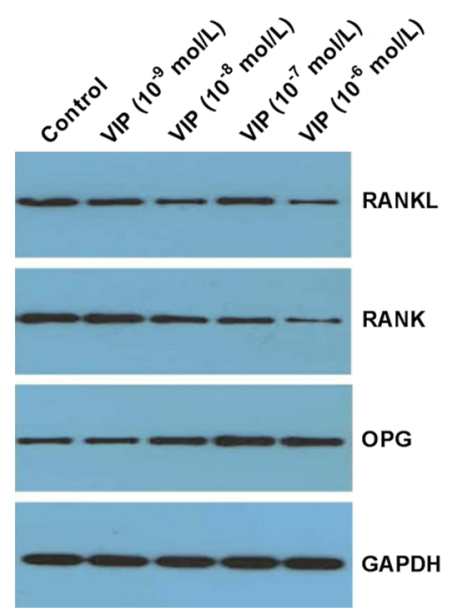

$\mathrm{H}$

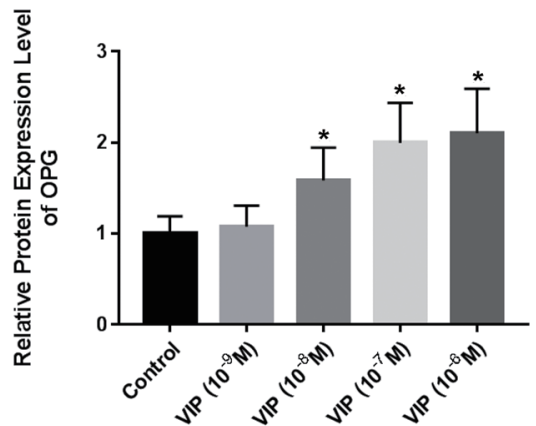

C

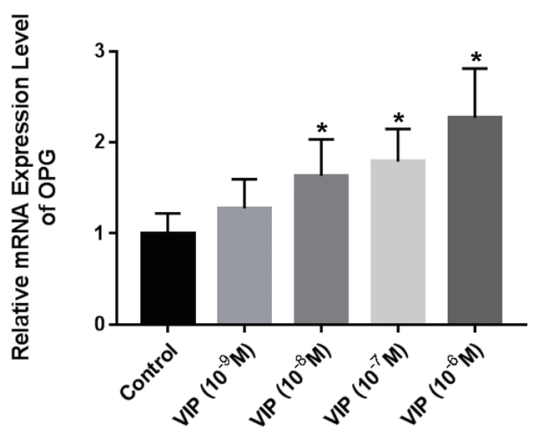

F

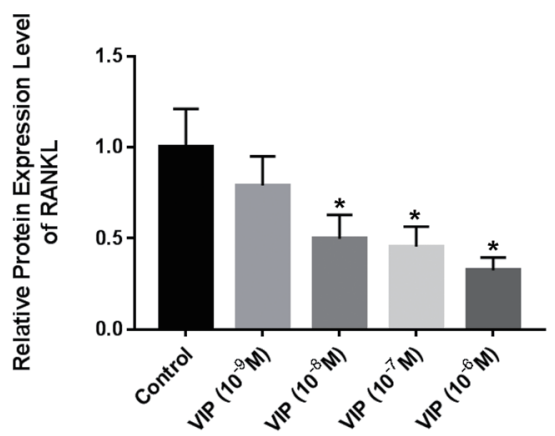

I

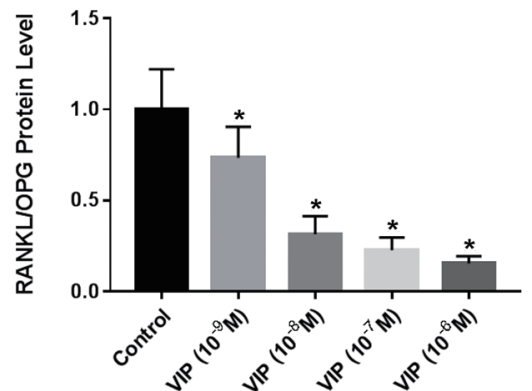

Figure 4 VIP affects the expression of RANK, RANKL, and $O P G$ in rat osteoclasts. Rat BMMs were treated with various doses of VIP $\left(10^{-9}\right.$ $\mathrm{M}, 10^{-8} \mathrm{M}, 10^{-7} \mathrm{M}$, or $10^{-6} \mathrm{M}$ ) under inducement with $30 \mathrm{ng} / \mathrm{mL} \mathrm{M}-\mathrm{CSF}$ and $50 \mathrm{ng} / \mathrm{mL}$ RANKL for 48 hours. Changes in (A) mRNA expression levels of RANKL; (B) mRNA expression levels of RANK; (C) mRNA expression levels of OPG; and (D) RANKL/OPG mRNA ratio with VIP stimulation. RANK, RANKL, and OPG protein expression were examined by western blot (E). (F) Protein expression levels of RANKL; $(\mathrm{G})$ protein expression levels of RANK; $(\mathrm{H})$ protein expression levels of OPG; and (I) ratio of RANKL/OPG with VIP stimulation. *, $\mathrm{P}<0.05$ vs. control. VIP, vasoactive intestinal peptide; RANK, receptor activator of nuclear factor-k; RANKL, receptor activator of nuclear factor $\mathrm{\kappa B}$ ligand; OPG, osteoprotegerin; BMMs, bone marrow-derived macrophages; M-CSF, macrophage colonystimulating factor. 
A

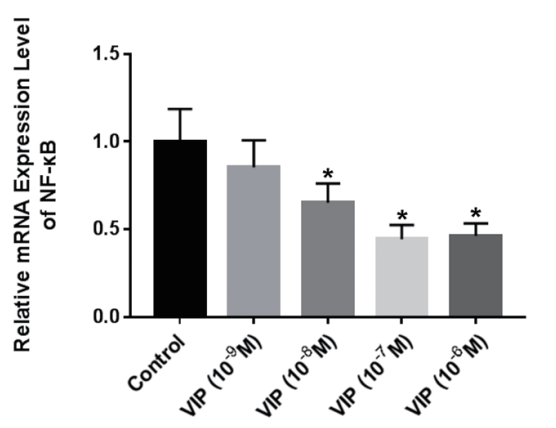

D

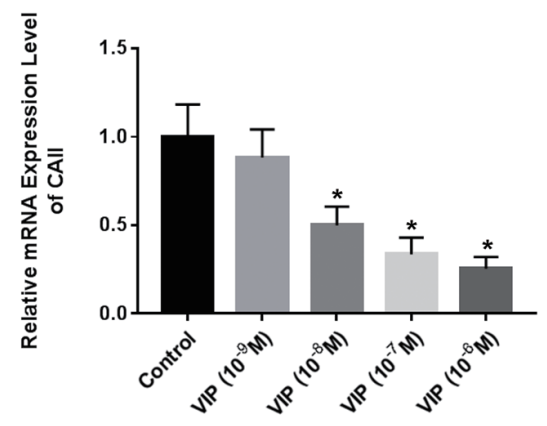

G

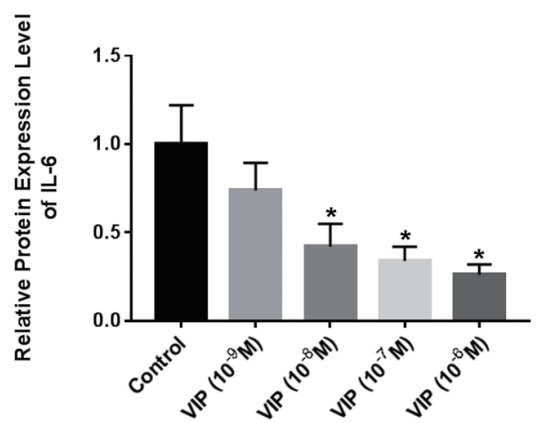

B

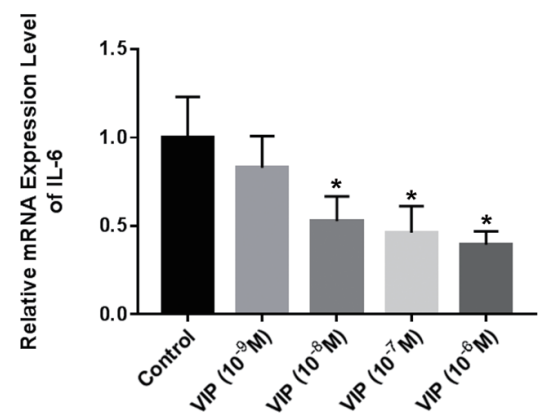

$\mathrm{E}$
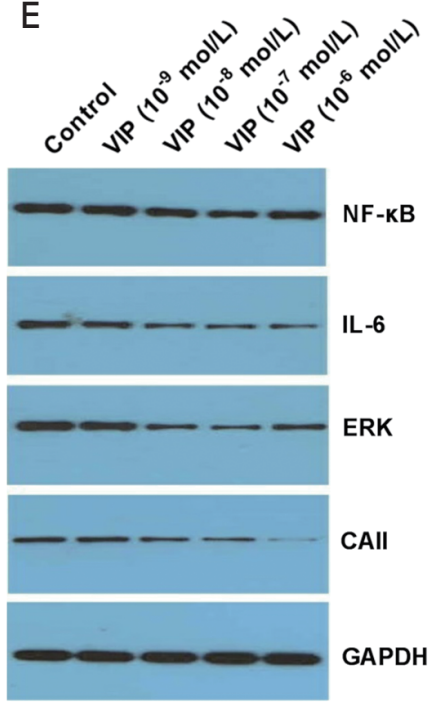

$\mathrm{H}$

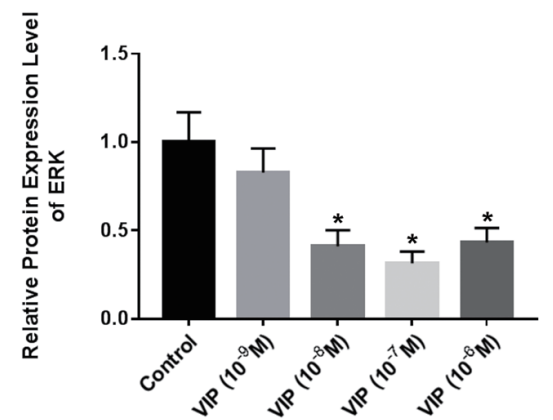

C

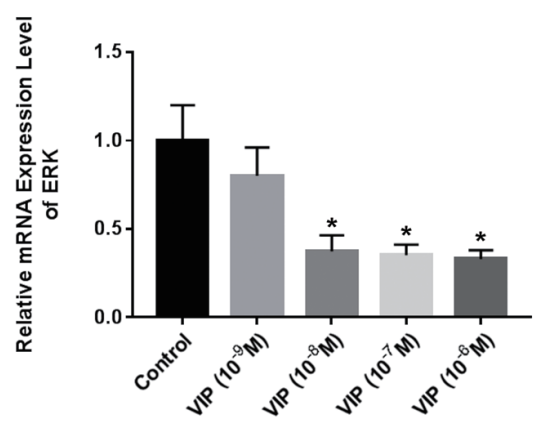

$\mathrm{F}$

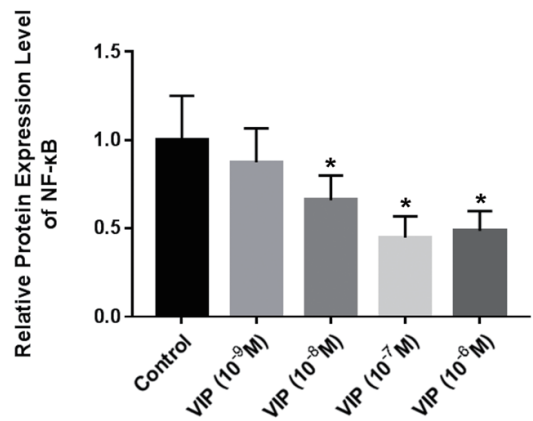

I

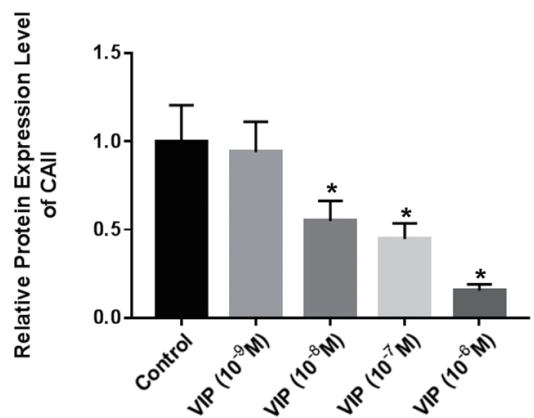

Figure 5 VIP suppressed the ERK and NF- $\mathrm{kB}$ signaling pathways in osteoclast formation induced by RANKL. Rat BMMs were treated with various doses of VIP $\left(10^{-9} \mathrm{M}, 10^{-8} \mathrm{M}, 10^{-7} \mathrm{M}\right.$, or $\left.10^{-6} \mathrm{M}\right)$ under inducement with $30 \mathrm{ng} / \mathrm{mL}$ M-CSF and $50 \mathrm{ng} / \mathrm{mL}$ RANKL for 48 hours. Changes in (A) mRNA expression levels of NF-kB; (B) mRNA expression levels of IL-6; (C) mRNA expression levels of ERK; and (D) mRNA expression levels of CAII after VIP stimulation. Protein expression levels of NF- $\mathrm{kB}$, IL-6, ERK, and CAII were detected by western blot (E). Changes in (F) Protein expression levels of NF-kB; (G) protein expression levels of IL-6; (H) protein expression levels of ERK; and (I) protein expression levels of CAII after VIP stimulation. *, $\mathrm{P}<0.05$ vs. control. VIP, vasoactive intestinal peptide; ERK, extracellular

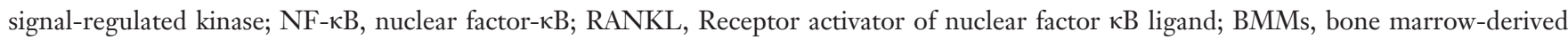
macrophages; CAII, carbonic anhydrase II; IL-6, interleukin 6. 
A

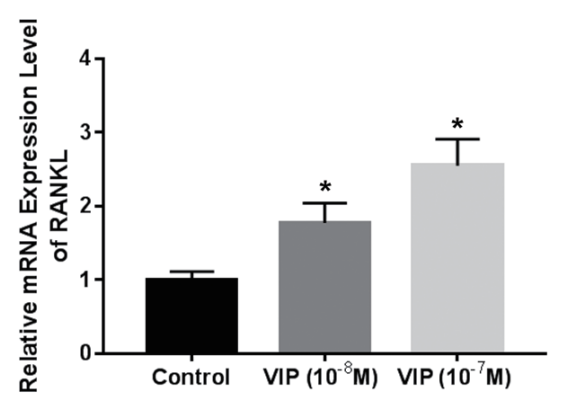

D

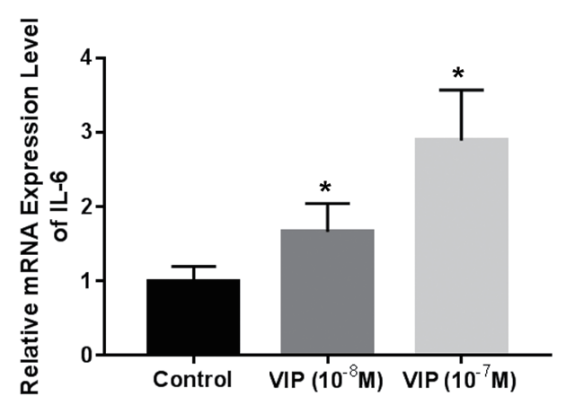

G

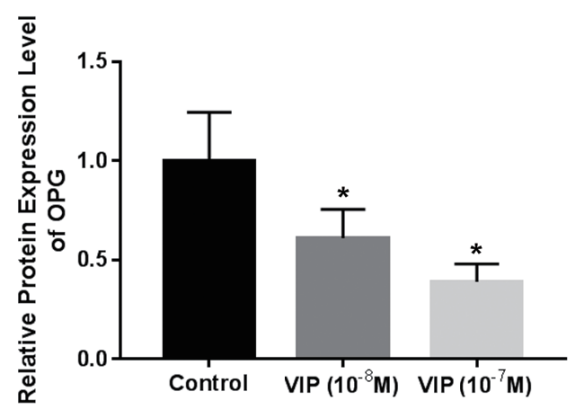

B

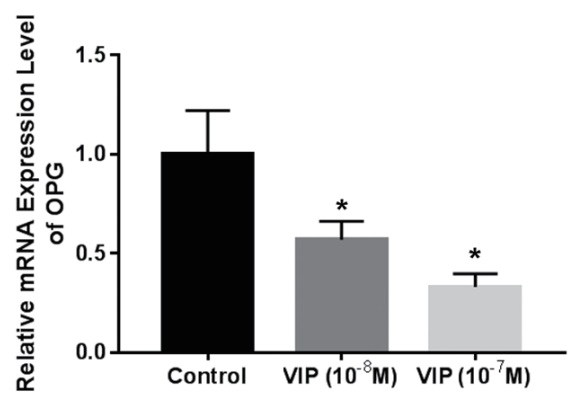

E
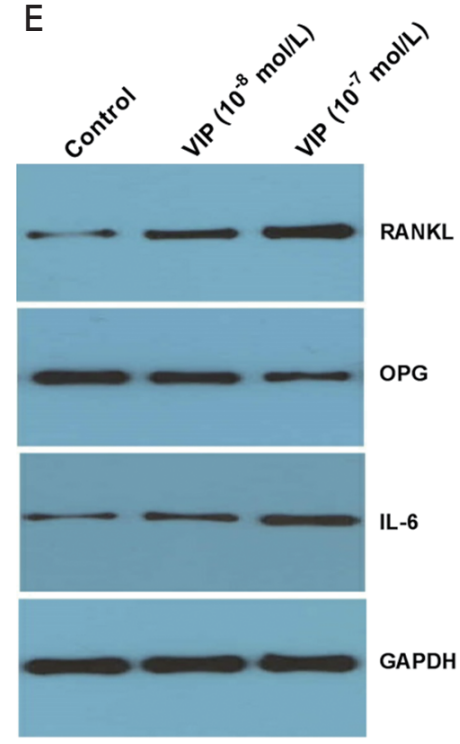

$\mathrm{H}$

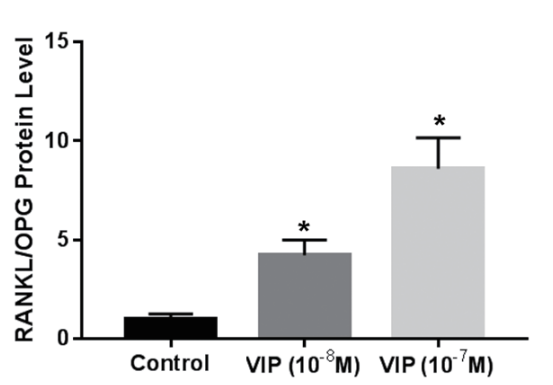

C

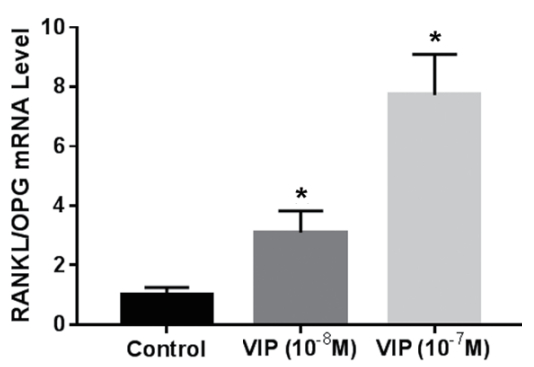

F

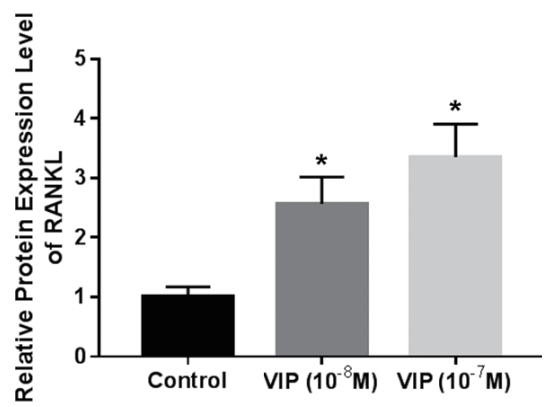

Figure 6 VIP affected RANKL, IL-6, and OPG expressions in the osteoblastic cell line ROS 17/2.8. ROS 17/2.8 cells were treated with various concentrations of VIP $\left(10^{-8} \mathrm{M}, 10^{-7} \mathrm{M}\right)$ exposed to $30 \mathrm{ng} / \mathrm{mL} \mathrm{M}$-CSF and $50 \mathrm{ng} / \mathrm{mL}$ RANKL for 48 hours. Changes in (A) mRNA expression levels of RANKL; (B) mRNA expression levels of OPG; (C) ratio of RANKL/OPG mRNA; and (D) IL-6 mRNA after VIP stimulation. RANKL, OPG, and IL-6 protein expression levels were examined by western blot (E). (F) Protein expression levels of RANKL; (G) protein expression levels of OPG; (H) ratio of RANKL/OPG protein; and (I) protein expression levels of IL-6 after VIP stimulation. *, $\mathrm{P}<0.05$ vs. control. VIP, vasoactive intestinal peptide; RANKL, receptor activator of nuclear factor $\kappa \mathrm{B}$ ligand; IL-6, interleukin 6; OPG, osteoprotegerin; M-CSF, macrophage colony-stimulating factor. 

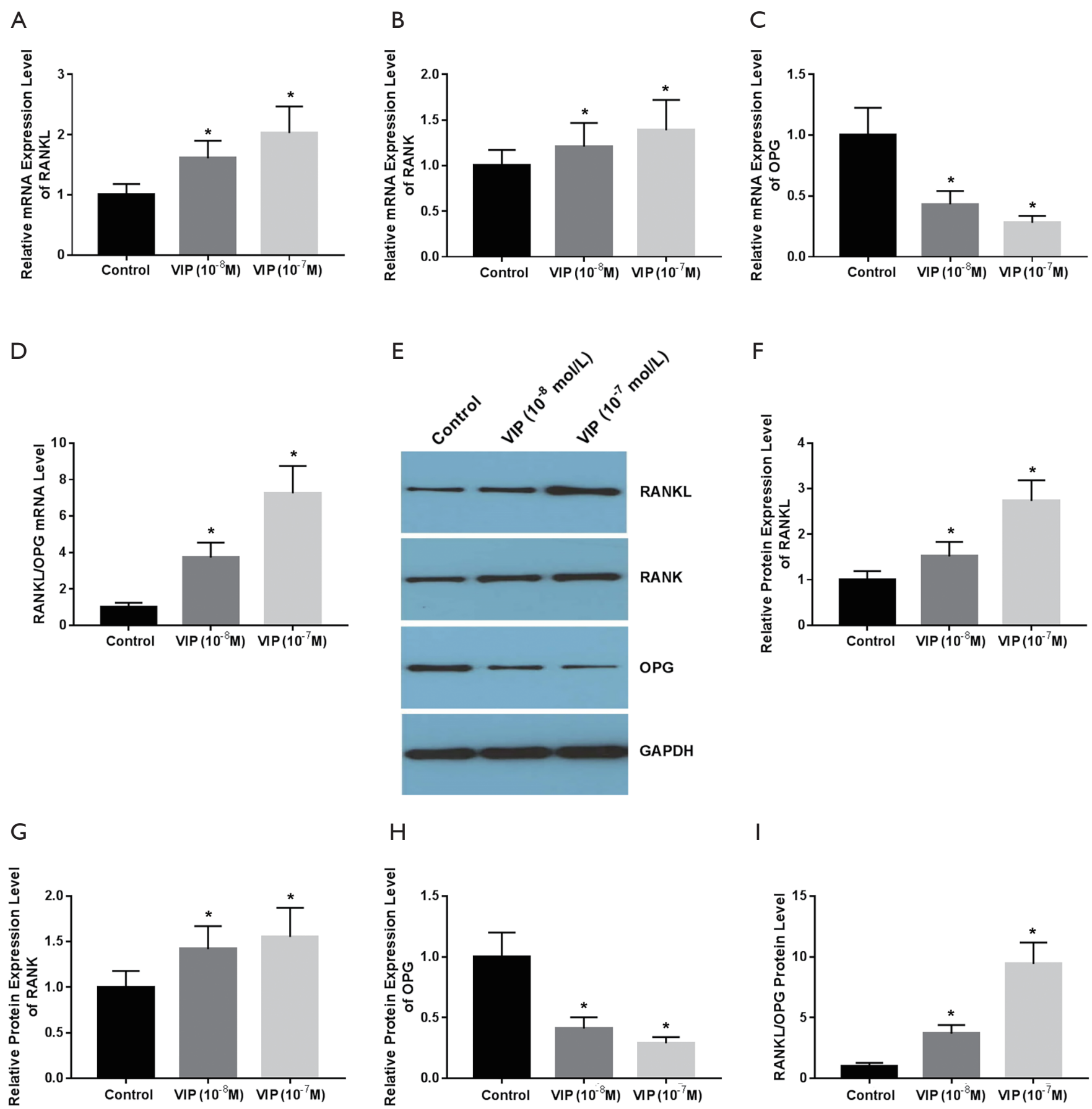

Figure 7 Effect of VIP on RANKL, RANK, and OPG expressions in co-culture system of ROS 17/2.8 and rat osteoclast precursor cells. ROS 17/2.8 and rat osteoclast precursor cells were treated with various concentrations of VIP $\left(10^{-8} \mathrm{M}, 10^{-7} \mathrm{M}\right)$ exposed to $30 \mathrm{ng} / \mathrm{mL}$ M-CSF and $50 \mathrm{ng} / \mathrm{mL}$ RANKLfor 48 hours. Changes in (A) mRNA expression levels of RANKL; (B) mRNA expression levels of RANK; (C) mRNA expression levels of OPG; and (D) ratio of RANKL/OPG mRNA after VIP stimulation. RANKL, RANK and OPG protein expression levels were examined by western blot (E). (F) Protein expression levels of RANKL; (G) protein expression levels of RANK; (H) protein expression levels of OPG; and (I) ratio of RANKL/OPG protein after VIP stimulation. *, P<0.05 vs. control. VIP, vasoactive intestinal peptide; RANK, receptor activator of nuclear factor-k; RANKL, receptor activator of nuclear factor $\kappa \mathrm{B}$ ligand; OPG, osteoprotegerin; M-CSF, macrophage colony-stimulating factor. 
A

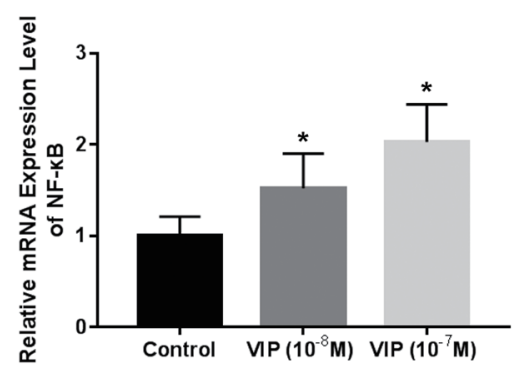

D

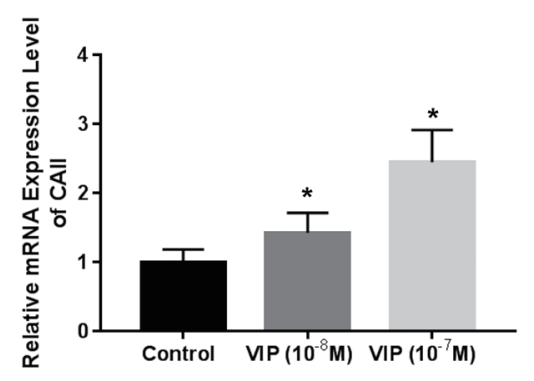

G

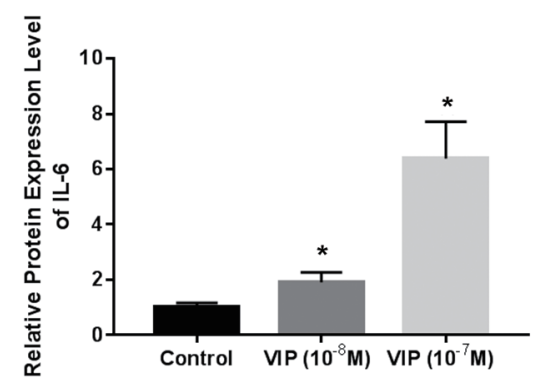

B

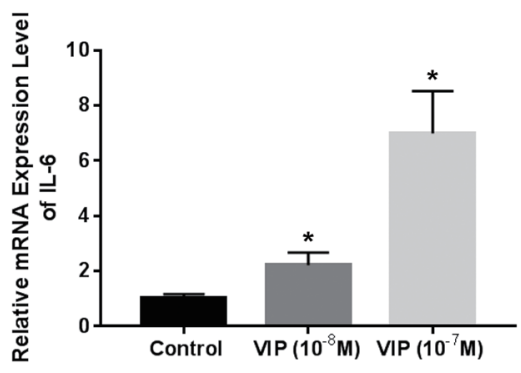

E

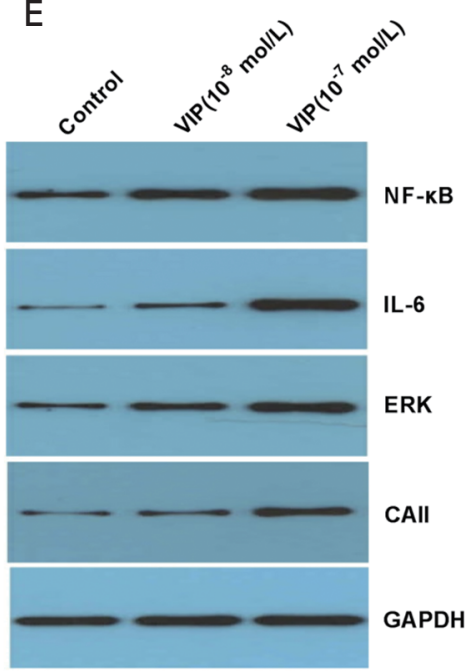

$\mathrm{H}$

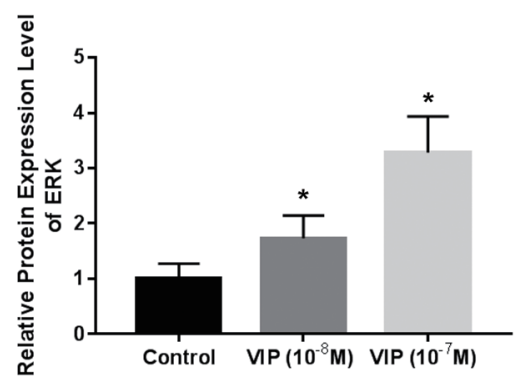

C

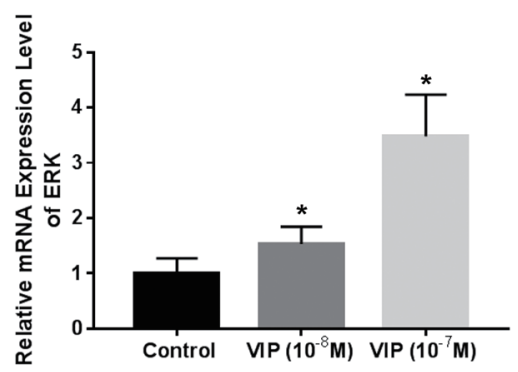

F

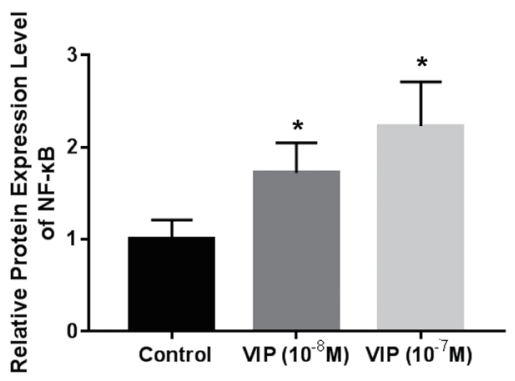

I

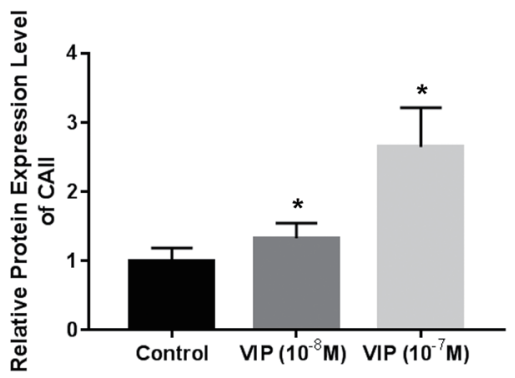

Figure 8 Effect of VIP on NF- $\mathrm{KB}$ and ERK signaling pathways induced by RANKL in the co-culture of ROS 17/2.8 and rat osteoclast precursor cells. ROS $17 / 2.8$ and rat osteoclast precursor cells were treated with various concentrations of VIP $\left(10^{-8} \mathrm{M}, 10^{-7} \mathrm{M}\right)$ under inducement with $30 \mathrm{ng} / \mathrm{mL}$ M-CSF and $50 \mathrm{ng} / \mathrm{mL}$ RANKL for 48 hours. Changes in (A) mRNA expression levels of NF- $\mathrm{kB}$; (B) mRNA expression levels of IL-6; (C) mRNA expression levels of ERK; and (D) mRNA expression levels of CAII after VIP stimulation. NF- $\mathrm{kB}$, IL-6, ERK, and CAII protein expression levels were examined by western blot (E). Change in (F) Protein expression levels of NF-kB; (G) protein expression levels of IL-6; (H) protein expression levels of ERK; and (I) protein expression levels of CAII after VIP stimulation.

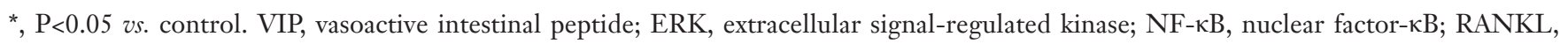
receptor activator of nuclear factor $\mathrm{\kappa B}$ ligand; BMMs, bone marrow-derived macrophages; CAII, carbonic anhydrase II; IL-6, interleukin 6. 
fibrous dysplasia. CPT commonly manifests as tibial and/or fibular fractures and tibial deformities (which often present as anterolateral bowing) (37). Until recently, the pathogenesis of CPT was not well understood. Many attempts have been made to elucidate the development of pseudo-arthropathy. Cho et al. concluded that the periosteum of CPT results in reduced osteogenesis and increased osteoblast activity relative to the normal periosteum, leading to bone graft absorption and failure of fractures to heal (38). RANKL is found in a variety of cells and acts as an essential molecule for osteoclast differentiation; thus, further study of the mechanism of bone erosion mediated by RANKL-induced osteoclasts is needed to gain a deeper understanding of the pathogenesis of bone resorption in CPT.

VIP has been proved to modulate various functions of bone cells. It also influences the formation and bone resorption activity of osteoclasts (35), as well as osteoblast anabolic processes (34). VIP was demonstrated to facilitate the generation of mineralized nodules derived from osteoblasts (34), and to trigger the transient suppression and delayed stimulation of osteoclast activity (39). Our data demonstrated that VIP treatment suppressed osteoclast differentiation in vitro but induced osteoclast differentiation in osteoblast cell line and osteoclast precursor cell cocultures.

To determine the effects of VIP on osteoclastogenesis, we measured the number of resorbed pits as an index for osteoclast formation. VIP markedly decreased the number of resorption pits in a concentration- and time-dependent way compared to the controls (Figure $2 A, B, C ; \mathrm{P}<0.05$ ). These results indicated that neuropeptide VIP is essential for inhibiting bone resorption of osteoclasts. At the same time, the results of our MTT assays showed that VIP has no effect on cell viability. These results suggest that VIP diminishes osteoclasts differentiation without affecting the numbers of osteoclast precursor cells.

Modulation of the RANKL/OPG signaling pathway was demonstrated to participate in the suppression of bone resorptive activities upon application of neuropeptide. VIP has previously been reported to decrease the stimulatory influence of D3 on the expression of RANKL and reverse the decrease of OPG expression in BMCs. Additionally, VIP can decrease the expression of RANK (30). All of the effects described above may contribute to the repression of osteoclastogenesis by VIP. The expression levels of RANKL and RANK in rat osteoclasts were found to be reduced by VIP treatment, and the effect of VIP on $O P G$ expression further confirmed its inhibitive function on osteoclast differentiation.

Stimulation of osteoblasts by VIP treatment enhances mineralization in the early stage but does not increase end-point mineralization, which indicates that VIP can promote the differentiation of committed osteoblasts but has no obvious promoting effect on the differentiation of uncommitted cells (34). To assess whether VIP treatment can regulate osteoclastogenesis, we explored the influence of VIP treatment on OPG, RANKL, and IL-6 expression in the rat osteosarcoma cell line ROS 17/2.8. The results showed that VIP treatment led to the down-regulation of $O P G$ and the up-regulation of RANKL. Furthermore, the expression levels of $I L-6$ were increased, indicating the involvement of the NF- $\mathrm{\kappa B}$ signaling pathway.

Since osteoblasts and osteoclast precursor cells coexist in vivo, a co-culture system of ROS 17/2.8 and rat osteoclast precursor cells was established to investigate the role of VIP in this case. When isolated rat osteoclasts were mixed with a large number of osteoblasts or stromal cells, no significant contraction or movement reduction was observed in the osteoclasts after VIP treatment for $120 \mathrm{~h}$. The results of the resorption pit assay indicated that VIP could remarkably increase the number of resorption pits (39). Our results showed that in the ROS 17/2.8 and rat osteoclast precursor cell co-culture system, the expression levels of osteoclastic factors such as RANKL and RANK were increased, whereas the expression of $O P G$ was reduced, by VIP. Thus, the down-regulation of OPG and up-regulation of RANKL are responsible for the enhanced bone erosion and loss in CPT. Furthermore, the RANKL / OPG ratio, which reflects the erosive properties of CPT, is highly increased after VIP treatment, which is responsible for the bone erosion associated with CPT.

The mitogen-activated protein kinase (MAPK) and the transcription factor nuclear factor kappa-lightchain-enhancer of activated B cells (NF- $\mathrm{BB})$ signaling pathways may be involved in the effect of VIP on bone erosion in CPT. NF- $\mathrm{KB}$ contributes to the osteoclast differentiation and its suppression blocks RANKL-induced osteoclastogenesis (28). RANKL is capable of activating the MAPK (ERK, JNK, and p38) pathways in osteoclasts and osteoclast precursors (40). The MAPK signaling pathways have been shown to play a pivotal role in osteoclastogenesis through their induction of key transcription factors involved in osteoclast differentiation, including NFATc1 and c-Fos $(41,42)$. NFATc1 is a major regulator of RANKL-induced osteoclast differentiation. The expression of NFATc1 appeared to be induced by RANKL in a dose dependent 
way. These results suggest that RANKL may regulate osteoclast activation and subsequent bone resorption through RANK and NFATc1 pathway (43). As reported here, NF- $\mathrm{KB}$ and ERK activity in rat osteoclasts and in co-cultured ROS 17/2.8 and rat osteoclast precursor cells was affected by VIP. Our understanding of the signaling pathways involved in CPT could pave the way for the development of novel drug strategies involving MAPK and NF- $\kappa \mathrm{B}$ inhibitors.

VIP receptors mediate the transient inhibitory effect of VIP on osteoclast activity. According to the results of previous studies, it was found that murine osteoclasts express VIP-1R and PACAP-R, but not VIP-2R (33). However, which receptor plays a major role or both receptors are indispensable is still a subject worthy of further exploration.

According to previous studies, VIP plays an immunomodulatory role in a variety of diseases. For instance, VIP modulates the imbalance between Th subsets in RA, decreasing pathogenic Th1 and Th17 subsets and favoring Th2 or Treg profile during the differentiation/ polarization of naïve or memory Th cells (44). VIP works via decreasing proinflammatory cytokines and other mediators involved in the differentiation and activation of osteoclast-precursor cells, and increasing anti-inflammatory cytokines. VIP-induced modification of the cell types present in the joint, which would decrease the amount of Th1-lymphocytes that express RANKL (45). All these suggest that VIP can play a pivotal role in the prevention and treatment of diseases through a variety of immune regulatory mechanisms, and also provide valuable directions for our future research.

In conclusion, we have demonstrated that the neuropeptide VIP plays a critical role in regulating the bone resorption activity of osteoclasts via the RANKL/OPG and NF- $\mathrm{KB}$ and ERK pathways. A deeper understanding of the neural regulatory aspect of bone remodeling may provide new insights for potential treatment strategies for CPT.

\section{Acknowledgments}

Funding: None.

\section{Footnote}

Reporting Checklist: The authors have completed the MDAR reporting checklist. Available at http://dx.doi.org/10.21037/ atm-20-7607
Data Sharing Statement: Available at http://dx.doi. org/10.21037/atm-20-7607

Conflicts of Interest: All authors have completed the ICMJE uniform disclosure form (available at http://dx.doi. org/10.21037/atm-20-7607). The authors have no conflicts of interest to declare.

Ethical Statement: The authors are accountable for all aspects of the work in ensuring that questions related to the accuracy or integrity of any part of the work are appropriately investigated and resolved. All animal experiments were performed in accordance with the guidelines for animal care and approved by The First Affiliated Hospital of Shandong First Medical University.

Open Access Statement: This is an Open Access article distributed in accordance with the Creative Commons Attribution-NonCommercial-NoDerivs 4.0 International License (CC BY-NC-ND 4.0), which permits the noncommercial replication and distribution of the article with the strict proviso that no changes or edits are made and the original work is properly cited (including links to both the formal publication through the relevant DOI and the license). See: https://creativecommons.org/licenses/by-nc-nd/4.0/.

\section{References}

1. Tiedemann K, Hussein O, Komarova S. Role of Altered Metabolic Microenvironment in Osteolytic Metastasis. Front Cell Dev Biol 2020;8:435.

2. Kim BJ, Koh JM. Coupling factors involved in preserving bone balance. Cell Mol Life Sci 2019;76:1243-53.

3. Park-Min KH. Mechanisms involved in normal and pathological osteoclastogenesis. Cell Mol Life Sci 2018;75:2519-28.

4. Letarouilly JG, Broux O, Clabaut A. New insights into the epigenetics of osteoporosis. Genomics 2019;111:793-8.

5. Shapiro G, Fishleder J, Stepensky P, et al. Skeletal Changes After Hematopoietic Stem Cell Transplantation in Osteopetrosis. J Bone Miner Res 2020;35:1645-51.

6. Zhu GH, Mei HB, He RG, et al. Effect of distraction osteogenesis in patient with tibial shortening after initial union of Congenital Pseudarthrosis of the Tibia (CPT): a preliminary study. BMC Musculoskelet Disord 2015;16:216.

7. Galve-Roperh I, Chiurchiù V, Díaz-Alonso J, et al. Cannabinoid receptor signaling in progenitor/stem 
cell proliferation and differentiation. Prog Lipid Res 2013;52:633-50.

8. Persson E, Lerner U. The neuropeptide VIP potentiates IL-6 production induced by proinflammatory osteotropic cytokines in calvarial osteoblasts and the osteoblastic cell line MC3T3-E1. Biochem Biophys Res Commun 2005;335:705-11.

9. Diaz-Solano D, Wittig O, Mota J, et al. Isolation and Characterization of Multipotential Mesenchymal Stromal Cells from Congenital Pseudoarthrosis of the Tibia: Case Report. Anat Rec (Hoboken) 2015;298:1804-14.

10. El-Hoss J, Sullivan K, Cheng T, et al. A murine model of neurofibromatosis type 1 tibial pseudarthrosis featuring proliferative fibrous tissue and osteoclast-like cells. J Bone Miner Res 2012;27:68-78.

11. Teitelbaum SL, Ross FP. Genetic regulation of osteoclast development and function. Nat Rev Genet 2003;4:638-49.

12. Portal-Núñez S, Mediero A, Esbrit P, et al. Unexpected Bone Formation Produced by RANKL Blockade. Trends Endocrinol Metab 2017;28:695-704.

13. Kearns AE, Khosla S, Kostenuik PJ. Receptor activator of nuclear factor kappaB ligand and osteoprotegerin regulation of bone remodeling in health and disease. Endocr Rev 2008;29:155-92.

14. Arai F, Miyamoto T, Ohneda O, et al. Commitment and differentiation of osteoclast precursor cells by the sequential expression of c-Fms and receptor activator of nuclear factor kappaB (RANK) receptors. J Exp Med 1999; 190:1741-54.

15. Ross FP, Teitelbaum SL. alphavbeta3 and macrophage colony-stimulating factor: partners in osteoclast biology. Immunol Rev 2005;208:88-105.

16. Dai XM, Ryan GR, Hapel AJ, et al. Targeted disruption of the mouse colony-stimulating factor 1 receptor gene results in osteopetrosis, mononuclear phagocyte deficiency, increased primitive progenitor cell frequencies, and reproductive defects. Blood 2002;99:111-20.

17. Li J, Sarosi I, Yan X, et al. RANK is the intrinsic hematopoietic cell surface receptor that controls osteoclastogenesis and regulation of bone mass and calcium metabolism. Proc Natl Acad Sci U S A 2000;97:1566-71.

18. Kong YY, Yoshida H, Sarosi I, et al. OPGL is a key regulator of osteoclastogenesis, lymphocyte development and lymph-node organogenesis. Nature 1999;397:315-23.

19. Dougall WC, Glaccum M, Charrier K, et al. RANK is essential for osteoclast and lymph node development. Genes Dev 1999;13:2412-24.

20. Bucay N, Sarosi I, Dunstan C, et al. osteoprotegerin- deficient mice develop early onset osteoporosis and arterial calcification. Genes Dev 1998;12:1260-8.

21. Huang J, Lin D, Wei Z, et al. Parathyroid Hormone Derivative with Reduced Osteoclastic Activity Promoted Bone Regeneration via Synergistic Bone Remodeling and Angiogenesis. Small 2020;16:e1905876.

22. Conaway HH, Henning P, Lie A, et al. Glucocorticoids employ the monomeric glucocorticoid receptor to potentiate vitamin D and parathyroid hormone-induced osteoclastogenesis. FASEB J 2019;33:14394-409.

23. Matsushita Y, Nagata M, Kozloff K, et al. A Wntmediated transformation of the bone marrow stromal cell identity orchestrates skeletal regeneration. Nat. Commun 2020;11:332.

24. Zhang Y, Gu X, Li D, et al. METTL3 Regulates Osteoblast Differentiation and Inflammatory Response via Smad Signaling and MAPK Signaling. Int J Mol Sci 2019;21.

25. Huang S, Li Z, Liu Y, et al. Neural regulation of bone remodeling: Identifying novel neural molecules and pathways between brain and bone. J Cell Physiol 2019;234:5466-77.

26. Gomariz RP, Lorenzo MJ, Cacicedo L, et al. Demonstration of immunoreactive vasoactive intestinal peptide (IR-VIP) and somatostatin (IR-SOM) in rat thymus. Brain Behav Immun 1990;4:151-61.

27. Ganea D, Hooper K, Kong W. The neuropeptide vasoactive intestinal peptide: direct effects on immune cells and involvement in inflammatory and autoimmune diseases. Acta Physiol (Oxf) 2015;213:442-52.

28. Lundberg P, Boström I, Mukohyama H, et al. Neurohormonal control of bone metabolism: vasoactive intestinal peptide stimulates alkaline phosphatase activity and mRNA expression in mouse calvarial osteoblasts as well as calcium accumulation mineralized bone nodules. Regul Pept 1999;85:47-58.

29. Hohmann EL, Elde RP, Rysavy JA, et al. Innervation of periosteum and bone by sympathetic vasoactive intestinal peptide-containing nerve fibers. Science 1986;232:868-71.

30. Lundberg P, Lie A, Bjurholm A, et al. Vasoactive intestinal peptide regulates osteoclast activity via specific binding sites on both osteoclasts and osteoblasts. Bone 2000;27:803-10.

31. Rawlings SR, Hezareh M. Pituitary adenylate cyclaseactivating polypeptide (PACAP) and PACAP/vasoactive intestinal polypeptide receptors: actions on the anterior pituitary gland. Endocr Rev 1996;17:4-29.

32. Lundberg P, Lundgren I, Mukohyama H, et al. 


\section{Page 16 of 16}

Vasoactive intestinal peptide (VIP)/pituitary adenylate cyclase-activating peptide receptor subtypes in mouse calvarial osteoblasts: presence of VIP-2 receptors and differentiation-induced expression of VIP-1 receptors. Endocrinology 2001;142:339-47.

33. Ransjö M, Lie A, Mukohyama H, et al. Microisolated mouse osteoclasts express VIP-1 and PACAP receptors. Biochem Biophys Res Commun 2000;274:400-4.

34. Mukohyama H, Ransjö M, Taniguchi $\mathrm{H}$, et al. The inhibitory effects of vasoactive intestinal peptide and pituitary adenylate cyclase-activating polypeptide on osteoclast formation are associated with upregulation of osteoprotegerin and downregulation of RANKL and RANK. Biochem Biophys Res Commun 2000;271:158-63.

35. Qu H, Wang K, Zhuang Y, et al. Expression of neuropeptide $\mathrm{Y}$ and vasoactive intestine peptide in pathological tissues of congenital pseudarthrosis of the tibia and its clinical significance. Int J Clin Exp Pathol 2016;9:8172-80.

36. Murrills RJ, Stein LS, Fey CP, et al. The effects of parathyroid hormone (PTH) and PTH-related peptide on osteoclast resorption of bone slices in vitro: an analysis of pit size and the resorption focus. Endocrinology 1990;127:2648-53.

37. Hefti F, Bollini G, Dungl P, et al. Congenital pseudarthrosis of the tibia: history, etiology, classification, and epidemiologic data. J Pediatr Orthop B 2000;9:11-5.

38. Cho TJ, Seo JB, Lee HR, et al. Biologic characteristics of fibrous hamartoma from congenital pseudarthrosis of the

Cite this article as: $\mathrm{Qu} \mathrm{H}$, Zhuang Y, Zhu L, Zhao Z, Wang $\mathrm{K}$. The effects of vasoactive intestinal peptide on RANKLinduced osteoclast formation. Ann Transl Med 2021;9(2):127. doi: 10.21037/atm-20-7607

\section{Qu et al. Effects of vasoactive intestinal peptide on osteoclasts}

tibia associated with neurofibromatosis type 1 . J Bone Joint Surg Am 2008;90:2735-44.

39. Sobacchi C, Menale C, Villa A. The RANKL-RANK Axis: A Bone to Thymus Round Trip. Front Immunol 2019;10:629.

40. Jimi E, Aoki K, Saito H, et al. Selective inhibition of NF-kappa B blocks osteoclastogenesis and prevents inflammatory bone destruction in vivo. Nat Med 2004;10:617-24.

41. Lee ZH, Kim HH. Signal transduction by receptor activator of nuclear factor kappa $B$ in osteoclasts. Biochem Biophys Res Commun 2003;305:211-4.

42. Huang H, Chang E, Ryu J, et al. Induction of c-Fos and NFATc1 during RANKL-stimulated osteoclast differentiation is mediated by the p38 signaling pathway. Biochem Biophys Res Commun 2006;351:99-105.

43. Fu J, Tao Y, Chen J, et al. Role of RANKL in the regulation of NFATc1 and c-Src mRNA expression in osteoclast-like cells. Mol Med Rep 2016;13:5163-8.

44. Gomariz RP, Juarranz Y, Abad C, et al. VIP-PACAP system in immunity: new insights for multitarget therapy. Ann N Y Acad Sci 2006;1070:51-74.

45. Delgado M, Martinez C, Pozo D, et al. Vasoactive intestinal peptide (VIP) and pituitary adenylate cyclaseactivation polypeptide (PACAP) protect mice from lethal endotoxemia through the inhibition of TNF-alpha and IL6. J Immunol 1999;162:1200-5.

(English Language Editor: J. Reynolds) 